lamp bulb, in case of replacement, needs attention. The filament must be horizontal and in the axis of the system. Whether or no this adjustment is correct, can be seen by looking at the face of the projection lens. The bright line of light should cut the lens horizontally into two equal parts. If this line is not true, the position of the filament must be altered. The lamp mount is pivoted at its front end on a horizontal axis on trunnions. At the back there are a screw and a spring on a vertical axis, the one lifting the back, the other allowing it to fall: As the back rises, so the filament is lowered, and vice versa, the movement being made by releasing or screwing in the lower screw. The distance between the lamp and the condenser system can be varied by loosening the large headed screw under the lamp end of the tube, and allowing the tube to slide over the lamp stem a little. This large-headed screw should be turned firmly when the adjustment has been made. Once the adjustment is obtained, it need not be altered until a new lamp is required.

It is better not to wear spectacles when using the lamp so that one's eye can be well within the shield of the ocular. It is well not to over-run the electric bulb, so when a new battery is used the switch to the rheostat should be turned on no more than twothirds until the battery weakens.

The hand slit-lamp is made by Messrs. Rayner of New Bond Street, London.

\title{
A NEW SLIT-LAMP
}

BY

E. GORDON MACKIE

SHEFFIELD

THE Slit-lamp has not hitherto been so widely used as its undoubted merits deserve. This is no doubt partly due to its many complicated adjustments which necessarily increase the cost of the apparatus. Quite a number of these are but rarely used in working the lamp, and some of them can be rendered unnecessary and expense saved by improvement in design. Its real value can only be appreciated by regular use and with the hope of inducing more of my colleagues to adopt this aid to their work I venture to bring to their notice the instrument here illustrated.

It has been made in accordance with the above ideas and having now been in use for over eighteen months and satisfied certain experienced slit-lamp observers may be said to be more than an experiment. 
The light source is a "Home Cinema Projection Lamp," used direct on the house current without resistance, and stocked by most electrical dealers. The optical system selects one of the filaments of the lamp grid and projects it in the Vogt manner, the beam being controlled by an adjustable slit, fine adjustment focussing screw and Arruga (vertical) screw in the ordinary manner. The selection of the filament is made in mounting the lamp in its

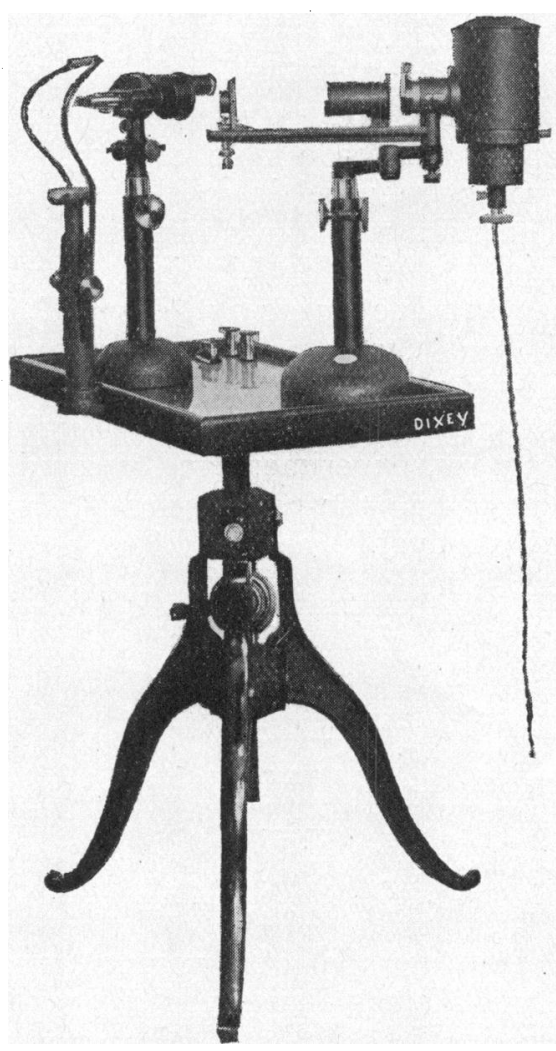

housing; the selected position is maintained by two clamping screws and remains indefinitely. A feeble light is a source of much unrewarded slit-lamp observation, and replacement of the old Nernst lamp by the Nitra lamp (of thrice the light value) was a landmark in the history of the instrument. Taking the latter lamp as a standard, the system adopted has been found to give 91 per cent. of the light value from a Nitra source at the point under examination, and this is fully adequate for all clinical purposes. For special purposes certain workers may require the 
highest degree of illumination obtainable, and this is now provided for by an alternative lighting system which, however, necessitates the use of a rheostat. The lamp and microscope are alike mounted on bases to slide on the glass-topped table. This method is less speedy than a mechanical device for lateral transit of the lamp, but it affords greater steadiness, and when the beam is adjusted it does not tend to pivot off its mark, so that there is no need to hold it constantly in position.

The beam can be applied all round the stand and I am obliged for a suggestion to this end made by $\mathrm{Mr}$. Harrison Butler.

The microscope affords a flat field and the magnification of $\times 20$ has been chosen as that of greatest usefulness for standard supply. Other magnifications are available (preferably by additional objectives), but are not required in routine work. If it is desired to study the endothelial cells the addition of objective $32 \mathrm{~mm}$. provides a magnification of $\times 28$ which is suitable for this purpose.

The instrument was made for me by Messrs. C. W. Dixey \& Son Ltd., of 15, Old Bond Street, who were responsible for many devices for simplifying mechanical design and for the successful means of cooling the $100 \mathrm{Watt}$ lamp. I am indebted to them for much painstaking work, experiment and ingenuity. As the complete instrument costs half the usual price it may permit of more extended use of this valuable means of ocular examination.

\section{ABSTRACTS}

\section{I. - PATHOLOGY}

(I) McKee, Joseph W. (Kansas City, Missouri).-Melanosarcoma at the limbus. Amer. Jl. of Ophthal., May, 1930.

(1) McKee's case was that of a woman, aged 31 years, who, when first seen, had a small deposit of pigment at the temporal side of the limbus in the right eye. There was a history of a similar deposit having been removed from the same area six years previously. Within six months, the pigmented area had become a soft, lobulated, almost black growth involving a quarter the circumference of the cornea. With the slit-lamp, it could be seen to be infiltrating the cornea. An application was made with the thermophore at $146^{\circ} \mathrm{F}$. for two minutes, and a month later a second application was made to the area not covered by the first one. Within three months all traces of the tumour had disappeared, and there has been no recurrence over a period of three years, vision remaining 20/20.

$$
\text { F. A. W-N. }
$$

